p. 15. My knowledge of Stempell's paper was derived from an abstract in which the osmotic aspect was chiefly emphasised. On reference to the original I find that this part of the process is obscured by a number of complicated subsidiary hypotheses.

University College, London.

\section{A Correction.}

SOME months ago Sir Ray Lankester was good enough to write to me in regard to the statement in my "System of Animate Nature" (I920) that he had spoken of evolution as "a chapter of accidents." $\mathrm{He}$ asked me to verify the quotation, and I thought I had only to turn to my book-shelves for a minute to find the passage. But in spite of some months of very agreeable and profitable re-reading of Sir Ray Lankester's writings, I have failed to verify the quotation, and the only thing to do is to apologise. Perhaps I should have seen that the phrase I ascribed to Sir Ray Lankester was inconsistent with such sentences as these:- "Thus then it appears that the conclusion that Man is a part of Nature is by no means equivalent to asserting that he has originated by 'blind chance'; it is, in fact, a specific assertion that he is the predestined outcome of an orderly, and to a large extent "perceptible,' mechanism" ("The Kingdom of Man," p. 9); and "They [the mental qualities which have evolved in Man] justify the view that Man forms a new departure in the gradual unfolding of Nature's predestined scheme" (op. cit., p. 25).

I yield to no one in my appreciation of the services which Sir Ray Lankester has rendered to zoology and biology, and I can only express my regret that in a busy life I made a mistake which amounts to an unintentional misrepresentation.

J. Arthur Thomson.

Natural History Department, Marischal

College, University of Aberdeen, August 16.

\section{Wrightson's Hypothesis of Audition.}

THE hypothesis advanced by the late Sir Thomas Wrightson in his book "An Enquiry into the Analytical Mechanism of the Internal Ear" has, it would seem, received such wide acceptance that the following comments upon it may be of interest.

Wrightson suggested that the appreciation by the ear of the constituent notes in a musical chord is due to the recognition and measurement by the brain of certain time intervals, which occur between the changes in motion of the air when it is transmitting music. In proof of this suggestion Wrightson gives graphic examples. First he takes two simple sine curves representing two musical notes, and from them he obtains a third curve which shows the motion of the air when both notes are sounding together. On this compound curve he marks distances between crests, troughs, and crossing points which are equal to the wave-lengths of the two separate notes.

From the identity of these distances Wrightson concludes that when the observer appreciates the constituent notes in a chord he does so by recognising the existence of these time relationships.

I find, however, that this proof loses its value, since it can be shown by trial that purely arbitrary wave-lengths are also represented in the compound curve as frequently as are those of the notes actually present.

It is scarcely possible, therefore, to accept Wrightson's explanation of the power of analysis possessed by the ear, since, all wave-lengths being equally repre- sented, there is no criterion by which the right notes can be recognised and the arbitrary ones excluded.

This criticism, considered in conjunction with that of Boring and Titchener (American Journal of Psychology, vol. xxxi., I920, pp. IoI-13), would seem to take from Wrightson's theory almost all the essential features which individualise it from the older telephone theory of Rutherford. H. HARTRIDGE.

\section{The Generation of Heath-fires.}

IT is the general practice to attribute the heathfires which have been so common of late to the careless dropping of matches or to the camp-fires of picnic-parties. But this is not always the cause. An instance came under my notice during the late hot weather which seems to be worth recording. I was walking along one of the ridges at Finchampstead, Berks, and to the south was a fairly steep slope of peaty heath land, giving rise here and there to clumps of bracken, but exposed each day to the sun's rays for many hours at a time. Noticing some smoke emerging from the soil, I turned down the slope to stamp out a possible fire, and I found that as soon as it was put out in one place it emerged elsewhere, a foot or so away. My companion and I repeated the process in many places, but soon we saw that the smoke was emerging from a hundred places, and our efforts were useless. Smoke was rising out of the peaty soil over an area of at least a quarter of a square mile, and another hour of the sun's heat might have been sufficient to result in the place breaking into flame.

From a note in Naruke of January 27 last, p. 704, in regard to the spontaneous burning of coal-seams in the United States, I see that the fine dust of lignite may ignite at $150^{\circ} \mathrm{C}$., and I suggest that in the case in point the finely divided carbonaceous soil may have been undergoing such changes under the heat of the sun, which may have brought up the temperature to something approaching this. Anyway, here was a considerable area smoking under the intense heat, and ignition could not have been far off.

South Norwood, S.E., August 13.

\section{Cornalith.}

IN the Bulletin of Agricultural Intelligence issued by the International Institute of Agriculture, just to hand, there is a précis of an article in the Annales de Gembloux under the heading "Plastic Materials with a Casein Basis: Galalith and Cornalith." The latter word is not in the N.E.D. or in the recently published "Dictionary of Scientific Terms." Galalith, or "milk-stone," is well known, and cornalith will be "horn-stone." The first sentence in this précis reads: "Galalith and cornalith, two substances made from casein that has been treated with formalin, are produced now in various countries, especially in France, where there are already several factories."

It is stated that, in order to diminish the cost of opaque articles made from casein treated with formaldehyde, the raw material is sometimes mixed with the refuse of horns, horsehair, and other nitrogenous matter. When this is done is it called "cornalith," and, if so, does the name or term correctly describe the material?

It is also stated that attempts have been made to use vegetable casein extracted from soya beans, as being less expensive than casein obtained from milk. Has this been successfully accomplished, and, if so, can the resulting plastic material be called "galalith," or is some other term used? R. HEDGER WALLACE.

August I6.

NO. 2704, VOL. IO7] 